\title{
Mental health of Syrian refugee adolescents: how far have we come?
}

\author{
Sinem Akgül1, ${ }^{1,5}$, Şenel Hüsnü², Orhan Derman ${ }^{1,5}$, Elif Özmert' ${ }^{3,5}$, Aysun Bideci ${ }^{4,5}$, \\ Enver Hasanoğlu ${ }^{5}$ \\ Divisions of ${ }^{1}$ Adolescent Medicine and ${ }^{3}$ Developmental Pediatrics, Department of Pediatrics, Hacettepe University Faculty \\ of Medicine, Ankara; ${ }^{2}$ Department of Psychology, Eastern Mediterranean University, Magosa, Cyprus; ${ }^{4}$ Department of \\ Pediatric Endocrinology, Gazi University Faculty of Medicine, Ankara; ${ }^{5}$ Turkish National Pediatrics Society, Ankara, \\ Turkey.E-mail: sinemhusnu@gmail.com \\ Received: 13th September 2019, Revised: 23rd September 2019, Accepted: 7th October 2019
}

SUMMARY: Akgül S, Hüsnü Ş, Derman O, Özmert E, Bideci A, Hasanoğlu E. Mental health of Syrian refugee adolescents: how far have we come? Turk J Pediatr 2019; 61: 839-845.

Among the consequences of war, its impact on the mental health of children and adolescents is one of the most significant. A previous study from our team evaluated the psychiatric symptoms of Syrian refugee adolescents living in one of Turkey's Temporary Accommodation Centers (TACs) in 2016. Findings suggested that mental health had been compromised in these teens. Since then many measures have been taken to address this problem. The aim of the current study was to re-assess the mental health status of adolescents living in the same center. A total of 76 adolescents (35 female, 41 male) aged between 12-18 years (14.2 \pm 0.83 years) received the Brief Symptom Inventory (BSI) which assessed their anxiety, depression, negative self-concept, somatization and hostility levels in addition to a Global Severity Index (GSI). Results $>1.0$ indicated psychopathological symptoms. All BSI sub-scores decreased from 2016 to 2019 showing significant improvement in psychopathological symptoms. The most significant change was in the GSI score which decreased from 2.15 to 0.8 . For the 2019 participants a significant correlation was found between years of stay at the camp and the depression subscale. Evaluation to assess gender differences found that adolescent girls reported significantly higher scores than males in anxiety, depression, somatization and the global severity index. This study has shown that interventions designed to tackle post-traumatic stress symptomology may have been effective in improving the mental health status of these teens and can provide a roadmap for tackling existing issues in vulnerable conditions. Additionally, females are under higher risk for psychopathology so gender targeted interventions may specifically be necessary to deal with such issues.

Key words: Syrian, refugee, adolescent, psychiatric symptoms, post-traumatic stress.

According to the United Nation's refugee agency, the U.N. High Commissioner for Refugees (UNHCR), as of February, 2019, there were a total of 3,644,342 registered Syrian refugees in Turkey. Of the 6.4 million Syrians who have fled their country since April 2011, nearly two-thirds are residing in Turkey, currently making Turkey the country with the highest number of refugees. ${ }^{1}$
As part of the temporary protection regime, Turkey pledged that it would welcome all people crossing the Syrian border to seek safety in Turkey and that it would provide for their humanitarian needs. Therefore, in order to shelter those displaced, Temporary Accommodation Centers (TAC) (previously called 'temporary protection center') have been established around Turkey. ${ }^{2}$ 
During times of conflict, children and adolescents are particularly vulnerable to mental health issues. These experiences in turn can lead to increased rates of depression, anxiety and post-traumatic stress disorder (PTSD). ${ }^{3}$ Prior research has shown that in contexts of conflict, individuals might experience a profound sense of loss and grief for family members who are either lost or deceased as well as for losses may they be material or emotional. Similarly, concern regarding the safety of family members in the ongoing crisis is considered to be a significant source of stress. ${ }^{4}$ Syrian refugees in particular may have been exposed to a multitude of warrelated traumas such as torture, rape, the death of family members as well as the destruction of their homes and livelihoods. ${ }^{5}$ Syrians have also endured risky methods for leaving Syria which might have also resulted in death of family members and unfair treatment on arrival to host country.

Those Syrian families who have experienced displacement may feel isolated from larger support systems within their pre-existing society ${ }^{6}$ and as they try to adapt to their new life they might feel estranged in their new foreign surroundings, longing for their homeland and prior identity as well as difficulty adapting to the living conditions in the countries of refuge. ${ }^{7,8}$

Psychological and social distress among refugees from Syria have been documented as manifesting in a wide range of emotional (sadness, grief, fear, frustration, anxiety), cognitive (loss of control, helplessness, hopelessness), physical (fatigue, insomnia, loss of appetite), behavioral and social (withdrawal, aggression and interpersonal issues) problems. ${ }^{9-13}$

Syrian refugees are therefore at large risk of developing mental disorders including depression, anxiety, PTSD and related somatic health symptoms. ${ }^{3,9,14}$ Children are the most vulnerable group and may be especially at risk of developing emotional and behavioral problems. In one such study with Syrian refugee children in Turkey, it was reported that nearly half of the children showed clinically significant levels of anxiety and withdrawal. ${ }^{15}$ Furthermore, prevalence rates for PTSD have been estimated to range from $34 \%$ to $52 \%$ in Syrian refugees. ${ }^{16,17}$

In 2016, a team from the Turkish National Pediatric Society (TNPS) conducted a study looking at the psychiatric symptoms of a group of Syrian refugee adolescents living in the Osmaniye Cevdetiye TAC. The findings of that study suggested that mental health had been compromised in these teens. Anxiety, depression, negative self-concept, hostility, and Global Severity Index (GSI) scores were significantly higher in the refugee group compared to the cut-off points for pathology. The scores for hostility and somatization were highest in the group that had been at the camp for longer than 4 years. ${ }^{18}$

Since then many measures have been taken to address this problem such as better living conditions in the TACs, greater opportunities for education and more extensive healthcare options. The aim of the current study was to re-assess the psychiatric symptoms and to additionally see if there were any influences of gender, age and duration of stay at the center on the PTSD levels of the adolescents.

\section{Material and Methods}

In March 2019, a delegation from the TNPS visited the same TAC in Osmaniye, Turkey. The TNPS conducts regular visits to the camp to evaluate the physical and psychosocial health status of children and adolescents living here and to educate and support the adolescents and their families. ${ }^{2}$ As part of this visit, information concerning this study was given to adolescents and their guardians and they were invited to participate; seventy-six Syrian adolescents currently attending the $8^{\text {th }}$ grade of the TACs school, aged between 12-17 years agreed to participate and were included in the study.

Permission to conduct the study was given by the Ministry of Health of Turkey (39942531), and the Ethical Committee of Ankara Children's Hematology-Oncology Training and Research Hospital, Ankara, Turkey approved the study (2017-089). Written informed consent was obtained from both the adolescents and their parents/guardians living in the TAC. 
Demographic characteristics of the participants, such as sex, age was noted. In addition, they were asked if any members of their family had been lost due to the war, and what their relationship was to that person. Finally, they were asked how long they had been in the camp.

All participants included in the study were given the Brief Symptom Inventory (BSI) ${ }^{19}$ The BSI consists of 53 items covering five symptom dimensions: anxiety, depression, negative self-concept, somatization, hostility and a GSI. The BSI is the short version of the SCL-R-90, which measures the same dimensions. ${ }^{20}$ Items for each dimension of the BSI were selected based on a factor analysis of the SCL-R-90, with the highest loading items on each dimension selected for the BSI. Responses on the BSI range from "none" to "very much," which are rated from 0 to 4 , respectively. It has been normed for persons aged 13 and over. It has a cut-off point for psychopathology, the GSI of 1.05. The BSI has been translated into Turkish and standardized for Turkish adolescents. ${ }^{21}$ The cut-off point for pathology was accepted as 1.0 according to BSI measurements. For pathologic psychiatric symptom analysis, the GSI was calculated by adding all the points and dividing by 53 ; results $>1.0$ indicated psychopathological symptoms, while patients with scores $<1$ were accepted as having no psychopathological symptoms. All participants were able to read and write in Turkish. BSI was self-administered by asking participants to take into consideration how they had been feeling over the last week.

\section{Results}

\section{Psychopathological symptoms of 2019 sample}

A correlation was conducted to see the relationship between age of adolescent, years of stay at the camp, loss of family member and the subscales of the BSI. The only significant correlation was that between years of stay at the camp and the depression subscale ( $r$ : 0.26 , p: 0.03). Significant correlations were obtained between all of the subscales of the BSI (Table I). An independent samples t-test was conducted to assess gender differences on the subscales. It was found that adolescent girls reported significantly higher scores than males in anxiety (p: 0.04), depression (p: $0.015)$, somatization (p: 0.01) and the GSI (p: 0.015). The mean scores, standard deviations, ranges and Cronbach's Alpha scores according to gender can be seen in Table II.

\section{Comparison of 2016 data}

In terms of demographic characteristics, the age of the participants in the 2016 data was $17.90 \pm 1.13$ years; whereas those in the current study were significantly younger (14.23 \pm 0.84 years, $\mathrm{p}<0.001)$. In the current study duration of stay at the camps ranged between $1-8$ years as opposed to the 2016 data whereby amount of stay ranged between 6 months and 5 years ( $p<0.001$ ). Out of the current sample, $30 \%$ reported having experienced loss of a family member as a result of the Syrian war, a similar finding was obtained in 2016 where $26.3 \%$ reported loss, but in the current sample, none

Table I. Correlations Between Study Variables.

\begin{tabular}{lccccccccc}
\hline & 1 & 2 & 3 & 4 & 5 & 6 & 7 & 8 & 9 \\
\hline 1. Age & - & & & & & & & \\
2. Duration of stay & -0.12 & - & & & & & & \\
3. Loss of family member & 0.08 & 0.17 & - & & & & & \\
4. Anxiety & -0.16 & 0.20 & 0.16 & - & & & & \\
5. Depression & -0.18 & $0.26^{*}$ & 0.20 & $0.89^{* *}$ & - & & & & \\
6. Negative self-concept & -0.15 & 0.17 & 0.21 & $0.80^{* *}$ & $0.84^{* *}$ & - & & \\
7. Somatization & -0.13 & 0.21 & 0.09 & $0.78^{* *}$ & $0.68^{* *}$ & $0.64^{* *}$ & - & \\
8. Hostility & -0.13 & 0.15 & 0.15 & $0.84^{* *}$ & $0.802^{* *}$ & $0.77^{* *}$ & $0.61^{* *}$ & - \\
9. Global Severity Index & -0.11 & 0.23 & 0.20 & $0.95^{* *}$ & $0.94^{* *}$ & $0.89^{* *}$ & $0.80^{* *}$ & $0.91^{* *}$ & - \\
\hline
\end{tabular}

${ }^{*} \mathrm{p}<0.05 ;{ }^{* *} \mathrm{p}<0.001$ 
Table II. Brief Symptom Inventory Score (2019) According to Gender.

\begin{tabular}{lcccccc}
\hline & Cronbach's Alpha & Mean \pm SD & Range & Mean \pm SD & Range & p value \\
\hline Anxiety & 0.89 & $0.93 \pm 0.96$ & $0-3.46$ & $0.55 \pm 0.55$ & $0-2.46$ & 0.04 \\
Depression & 0.87 & $1.13 \pm 1.04$ & $0-3.58$ & $0.63 \pm 0.60$ & $0-2.67$ & 0.015 \\
Negative self-concept & 0.82 & $0.95 \pm 0.69$ & $0-2.42$ & $0.75 \pm 0.75$ & $0-3.17$ & 0.26 \\
Somatization & 0.66 & $0.77 \pm 0.82$ & $0-2.89$ & $0.39 \pm 0.37$ & $0-1.44$ & 0.01 \\
Hostility & 0.79 & $0.98 \pm 0.98$ & $0-3.29$ & $0.77 \pm 0.69$ & $0-3.14$ & 0.30 \\
Global Severity Index & 0.96 & $1.05 \pm 0.82$ & $0-2.83$ & $0.61 \pm 0.56$ & $0-2.58$ & 0.015 \\
\hline
\end{tabular}

SD: standard deviation

Table III. Comparison of 2016 and 2019 Studies for Demographic Characteristics and Brief Symptom Inventory Scores.

\begin{tabular}{lccccc}
\hline & 2016 (n:76) & Range & 2019 (n:76) & Range & p value \\
\hline Age, year & $17.90 \pm 1.13$ & $16-20$ & $14.23 \pm 0.84$ & $12-17$ & $<0.001$ \\
Duration of stay at camp, year & $3.38 \pm 1.32$ & $0.6-5$ & $5.97 \pm 2.04$ & $1-8$ & $<0.001$ \\
Anxiety & $1.36 \pm 0.74$ & $0.25-3.42$ & $0.72 \pm 0.79$ & $0-3.46$ & $<0.001$ \\
Depression & $1.62 \pm 0.86$ & $0.29-3.71$ & $0.86 \pm 0.86$ & $0-3.58$ & $<0.001$ \\
Negative self-concept & $1.39 \pm 0.66$ & $0.38-3.46$ & $0.84 \pm 0.72$ & $0-3.17$ & $<0.001$ \\
Somatization & $1.65 \pm 0.73$ & $0.33-3.46$ & $0.56 \pm 0.64$ & $0-2.89$ & $<0.001$ \\
Hostility & $1.20 \pm 0.67$ & $0.22-3.44$ & $0.86 \pm 0.84$ & $0-3.29$ & $<0.001$ \\
Global Severity Index & $2.15 \pm 0.53$ & $1.26-3.55$ & $0.80 \pm 0.71$ & $0-2.83$ & $<0.001$ \\
\hline
\end{tabular}

SD: standard deviation

of the teens had lost a first degree relative to the war whereas in the 2016 study $11 \%$ had lost either a mother father or a sibling. Lastly, all participants in the current sample attended school, whereas only $64.5 \%$ reported being in school in 2016.

As for psychopathological symptoms, all subscores decreased from 2016 to 2019. The most significant change was in the GSI score which decreased from 2.15 to 0.8 , from 2016 to 2019, respectively (Table III).

\section{Discussion}

Migration resulting from war places a heavy toll on the lives of the children and adolescents that have been affected. Having to adapt to a new environment and culture in unfamiliar surroundings, facing challenges such as lack of food, shelter and sanitation, barriers of language, discrimination and poverty all contribute to this negative impact. ${ }^{22,23}$ The first study conducted by our team illustrated just this, as anxiety, depression, negative selfconcept, hostility, and GSI scores were above the cut-off points for psychopathology and scores were higher in the group that had stayed longer. On the contrary, the present study showed all sub-scores to be below the cutoff for pathology but also to have decreased from 2016 to 2019, which can be interpreted as an improvement of mental health. The most significant change was in the global severity score which decreased from 2.15 to 0.8 , from 2016 to 2019 , respectively.

There are many factors which could have contributed to this result but primarily we believe it is due to the changes that have occurred in the TACs as well as the interventions for social integration. One of the greatest changes is that to the structure of the centers where the tents have all been converted to containers. The camps resemble well established towns with primary and secondary schools, health clinics, community centers, supermarkets, play grounds and 
laundry rooms. Research shows that children who are not educated are more likely to feel isolation, hopelessness and marginalization making them easy targets for radicalization. ${ }^{4}$ Therefore, the addition of schools and the children's regular attendance to school might have played a significant role in the improvement of their self-reported well-being.

Another contributing factor that could have caused this difference may relate to contrasts in day-to-day stressors between populations as the first study was conducted in the more acute phase of the war whereas the second group are more settled. The protective aspects of daily routine such as, family networks, school, local familiarity may have also contributed to this difference.

Another significant difference between the two groups was the time spent at the camps. The second study group had spent a longer time at the camp. This may have resulted in better adaptation and acculturation, which was not assessed in this study, however is an important factor to consider. Differing rates of acculturation between the two groups could also explain this result as we would expect those living at the TACs longer to have adapted better to the cultural traits of their surroundings making life easier. ${ }^{24}$

Language difficulties have been highlighted as one of the barriers to Syrian refugees' ability to access many facilities such as education and healthcare. Language is an essential part of our individual and community lives, as well as being an essential tool for learning. A study from Germany showed the importance of language for the social inclusion of adolescent refugees with their native peers. ${ }^{25} \mathrm{~A}$ change made at this TAC is that all of the teachers in the camps are native speakers of Turkish and not Syrian teachers or volunteers. This in turn has increased Turkish literacy rates for refugee children. All the adolescents in this study were enrolled in a public school and were fluent in both Turkish and Arabic, whereas those in the first study had language difficulties. Language has a central role to play in helping refugees to address the effects of loss, displacement and trauma. Language also provides a voice for refugees so that their stories can be heard and understood.
A recent study looking at PTSD in Syrian migrant children and adolescents in Turkey showed that $71 \%$ suffered from severe PTSD. ${ }^{26}$ But what makes this study different is that, almost all the children had witnessed the death of at least one family member and had been separated from at least one family member, and more than half of the children had lost their mother or father. In our first study $11 \%$ of participants had also lost a first degree relative, whereas in this study none of the children had lost a parent or sibling due to the war. The experience of death and separation are factors that increase the severity of posttrauma which may also have contributed to the better results. ${ }^{3}$

Another difference in the two groups which can also be considered a limitation is the mean age group of the participants. The mean age of the adolescents in the second study were significantly younger with a mean age of 14.2 compared to 17.9 years. Age has long been understood to predict psychological distress and it has been consistently reported that older teenagers are more susceptible to mood disorders than younger ones. ${ }^{27}$ Dyregrov et $\mathrm{al}^{28}$ found younger children to be less influenced by intrusion. It might be argued that younger children are protected by their parents or relatives and are less likely to experience war related trauma whereas, in the older age groups, the war trauma might have disrupted the development of effective cognitive strategies and left them more open to the effects of the war.

Although the scores seem to have improved there is a lot that still needs to be done. Once again it was found that a significant correlation between years of stay at the camp and the depression subscale existed, suggesting that the more youth stay at the camps the worse it can be for their mental health. This implies that it is of importance to keep stay at the TACs to a minimum. Similar to the literature it was also found that anxiety, depression, somatization and the GSI was higher in adolescent girls when compared to boys. ${ }^{26,29}$ Many refugees, particularly children and women, are vulnerable to exploitation, gender-based violence or early forced marriages. ${ }^{30}$ Resettlement policies need to include strategies for mental health problems 
of refugees with a particular focus on girls.

In conclusion, even as efforts to ensure peace in Syria and to facilitate the return of Syrians to their homes continue it has also become clear that this does not look very likely any time soon. It has long been established that interventions can reduce the psychological impact of traumatic events. ${ }^{31}$ This study shows that the changes that have been made within the TACs to try and increase quality of life for these teens may have been effective in improving their mental health status.

\section{Acknowledgement}

The study received no funding but the routine visits to the camps were funded by the Turkish National Pediatric Society and the International Pediatric Association Foundation.

\section{REFERENCES}

1. United Nation's High Commissioner for Refugees (UNHCR), Syrian Regional Refugee Response. Available at: https://data2.unhcr.org/en/situations/ syria/location/113 (Accessed September 2019) .

2. Özmert EN, Derman O, Bideci A, et al. Syrian Children in Turkey: A model of action for national pediatric societies. Pediatrics 2019; 143: e20180539.

3. Hassan G, Ventevogel P, Jefee-Bahloul H, BarkilOteo A, Kirmayer LJ. Mental health and psychosocial wellbeing of Syrians affected by armed conflict. Epidemiol Psychiatr Sci 2016; 25: 129-141.

4. Sirin SR, Rogers-Sirin L. The Educational and Mental Health Needs of Syrian Refugee Children. Washington, DC: Migration Policy Institute, 2015.

5. Silove D, Ventevogel P, Rees S. The contemporary refugee crisis: an overview of mental health challenges. World Psychiatry 2017; 16: 130-139.

6. Thorleifsson C. Coping strategies among self-settled Syrians in Lebanon. Forced Migr Rev 2014: 23.

7. Moussa I. Identity crisis in the Syrian society during the crisis. Beirut: Thesis for executive master in Psychosocial Support \& Dialogue. IOM and Lebanese University, 2014.

8. Al Akash R, Boswall K. Listening to the voices of Syrian women refugees in Jordan: Ethnographies of displacement and emplacement. Refugee Voices Conference. Oxford University Refugee Studies Centre, 2014.

9. de Jong JT, Komproe IH, Van Ommeren M. Common mental disorders in postconflict settings. Lancet 2003; 361: 2128-2130.
10. Mollica RF, Cardozo BL, Osofsky HJ, Raphael B, Ager A, Salama P. Mental health in complex emergencies. Lancet 2004; 364: 2058-2067.

11. Momartin S, Silove D, Manicavasagar V, Steel Z Complicated grief in Bosnian refugees: Associations with posttraumatic stress disorder and depression. Compr Psychiatry 2004; 45: 475-482.

12. Pérez-Sales P. Assessment of trauma experiences, mental health and individual and community coping resources of refugee Syrian population displaced in North Bekaa (Lebanon). France/Spain: Medicin Du Monde 2012.

13. El-Masri, Harvey C, Garwood R. Shifting Sands: Changing gender roles among refugees in Lebanon. Joint Research Report London: ABAAD - Resource Centre for Gender Equality. Oxfam International, 2013

14. Fazel M, Wheeler J, Danesh J. Prevalence of serious mental disorder in 7000 refugees resettled in western countries: a systematic review. Lancet 2005; 365: 1309-1314.

15. Cartwright K, El-Khani A, Subryan A, Calam R. Establishing the feasibility of assessing the mental health of children displaced by the Syrian conflict. Glob Ment Health (Camb) 2015; 2: e8.

16. Alpak G, Unal A, Bulbul F, et al. Post-traumatic stress disorder among Syrian refugees in Turkey: a crosssectional study. Int J Psychiatry Clinical Pract 2015; 19: 45-50.

17. Chung MC, AlQarni N, AlMazrouei M, et al. The impact of trauma exposure characteristics on post-traumatic stress disorder and psychiatric comorbidity among Syrian refugees. Psychiatry Res 2018; 259: 310-315.

18. Derman O, Akgul S, Ataman E, et al. The rise of a hostile adolescent population: the Syrian refugee problem. Adol Psych 2017; 7: 83-88.

19. Derogatis L, Spencer PM. Brief Symptom Inventory: administration and procedures manual-I. Baltimore, MD: Clinical Psychometric Research Inc, 1982.

20. Derogatis LR, Cleary PA. Confirmation of the dimensional structure of the SCL-90: A study in construct validation. J Clin Psychol 1977; 33: 981989.

21. Sahin N, Durak A. Kisa semptom envanteri (Brief Symptom Invetory-BSI): Türk gençleri için uyarlanmasi. Türk Psikoloji Dergisi 1994; 9: 44-56.

22. Measham T, Guzder J, Rousseau C, Pacione L, BlaisMcPherson M, Nadeau L. Refugee children and their families: Supporting psychological well-being and positive adaptation following migration. Curr Probl Pediatr Adolesc Health Care 2014; 44: 208-215. 
23. Patel SG, Staudenmeyer AH, Wickham R, Firmender WM, Fields L, Miller AB. War-exposed newcomer adolescent immigrants facing daily life stressors in the United States. Int J Intercul Relat 2017; 60: 120131.

24. Hirani K, Payne D, Mutch R, Cherian S. Health of adolescent refugees resettling in high-income countries. Arch Dis Child 2016; 101: 670-676.

25. Beißert H, Gönültaş S, Mulvey KL. Social inclusion of refugee and native peers among adolescents: It is the language that matters! J Res Adolesc 2019; doi: $10-1111 /$ jora. 12518 .

26. Yayan EH. Post-traumatic stress disorder and mental health states of refugee children. Arch Psychiatr Nurs 2018; 32: 885-889.

27. Andrews JA, Lewinsohn PM. Suicidal attempts among older adolescents: prevalence and co-occurrence with psychiatric disorders. J Am Acad Child Adoles Psychiatry 1992; 31: 655-662.
28. Dyregrov A, Gjestad R, Raundalen M. Children exposed to warfare: a longitudinal study. J Traumatic Stress 2002; 15: 59-68.

29. Hodes M, Jagdev D, Chandra N, Cunniff A. Risk and resilience for psychological distress amongst unaccompanied asylum seeking adolescents. J Child Psychol Psychiatry 2008; 49: 723-732.

30. Bartels SA, Michael S, Roupetz S, et al. Making sense of child, early and forced marriage among Syrian refugee girls: a mixed methods study in Lebanon. BMJ Glob Health 2018; 3: e000509.

31. Tol WA, Barbui C, Galappatti A, et al. Mental health and psychosocial support in humanitarian settings: linking practice and research. Lancet 2011; 378: 1581-1591. 